\title{
Impact of antiretroviral drugs on PD-L1 expression and copy number gains with clinical outcomes in HIV-positive and -negative locally advanced cervical cancers
}

\author{
KONGSAK LOHARAMTAWEETHONG ${ }^{1}$, SONGKHUN VINYUVAT ${ }^{2}$, JIDAPA THAMMASIRI ${ }^{3}$, \\ SAKCHAI CHITPAKDEE ${ }^{4}$, CHALERMPAK SUPAKATITHAM $^{1}$ and NAPAPORN PURIPAT ${ }^{1}$
}

\author{
${ }^{1}$ Department of Anatomical Pathology, Faculty of Medicine, Vajira Hospital, Navamindradhiraj University, Bangkok 10300; \\ ${ }^{2}$ Department of Medical Services, Institute of Pathology, Ministry of Public Health; \\ ${ }^{3}$ Department of Pathology, National Cancer Institute; \\ ${ }^{4}$ Department of Pathology, Rajavithi Hospital, Bangkok 10400, Thailand
}

Received March 28, 2019; Accepted July 1, 2019

DOI: $10.3892 / 01.2019 .10963$

\begin{abstract}
Cervical cancer has become a leading cause of death in both HIV-infected and uninfected women. Previous studies have revealed that antiretroviral therapy (ART) possesses anti-human papillomavirus (HPV) and antitumour properties, potentially serving as an anticancer agent and improving functional immunity in HIV-positive individuals. However, to the best of our knowledge, no studies have examined the association between ART and the clinical outcome of patients with pre-existing invasive cervical cancer. The current study analysed 48 HIV-positive and 123 HIV-negative patients with locally advanced stage IB2-IVA cervical cancer between December 2008 and December 2016. Tumours were categorized based on programmed cell death-ligand 1 (PD-L1) immunoreactivity and copy number alterations in the PD-L1 gene, as determined by fluorescence in situ hybridization. The results revealed that ART-treated patients exhibited a lower prevalence of PD-L1 immunopositivity, PD-L1 amplification and polysomy compared with patients that did not receive ART and those that were HIV-negative. Furthermore, ART-treated patients with PD-L1 immunonegativity exhibited an improved recurrence-free survival (RFS) compared with patients that did not receive ART and HIV-negative individuals with PD-L1 immunopositivity ( $\mathrm{P}=0.041$ vs. $\mathrm{P}=0.030$ ). Additionally, ART-exposed patients with PD-L1 disomy demonstrated improved locoregional recurrence-free survival (LRR) when compared with HIV-negative patients with PD-L1
\end{abstract}

Correspondence to: Dr Kongsak Loharamtaweethong, Department of Anatomical Pathology, Faculty of Medicine, Vajira Hospital, Navamindradhiraj University, 681 Samsen Road, Dusit, Bangkok 10300, Thailand

E-mail: kongsakloharamtaweethong@hotmail.com

Key words: antiretroviral therapy, human immunodeficiency virus, programmed cell death-ligand 1 , clinical outcome, cervical cancer amplification and polysomy $(\mathrm{P}=0.039$ vs. $\mathrm{P}=0.007)$, RFS $(\mathrm{P}<0.001$ vs. $\mathrm{P}=0.006)$ and cancer-specific survival $(\mathrm{CSS})$ $(\mathrm{P}=0.021$ vs. $\mathrm{P}=0.025)$. ART-exposed patients with $\mathrm{PD}-\mathrm{L} 1$ disomy also exhibited improved RFS $(\mathrm{P}<0.001)$ and CSS $(\mathrm{P}<0.001)$ compared with HIV-negative patients with PD-L1 amplification. Improved LRRs were demonstrated in ART-exposed patients with PD-L1 disomy $(\mathrm{P}=0.028)$ compared with non-HIV patients with polysomy. Following multivariate analysis, International Federation of Gynaecology and Obstetrics stage and PD-L1 amplification were determined to be predictors of poor a RFS [hazard ratio (HR), 2.43; 95\% confidence interval $(\mathrm{CI}), 1.37-4.30 ; \mathrm{P}=0.002$ vs. HR, 7.03; 95\% CI, 2.79-17.74; $\mathrm{P}<0.001)$ and CSS (HR, 11.47; 95\% CI, 4.70-27.99; P<0.001 vs. HR, 4.05; 95\% CI, 1.64-9.98; $\mathrm{P}=0.002)$. However, only PD-L1 polysomy was determined to be a predictor of poor LRR (HR, 2.50; 95\% CI, 1.11-5.63; $\mathrm{P}=0.027$ ). HIV status was not associated with poor outcomes, as determined using Cox models. The results of the current study indicated that ART may be used for the treatment of cervical cancer in both HIV-infected and uninfected patients. However, additional research is required to further elucidate these results.

\section{Introduction}

Cervical cancer is one of the most common cancer types in women living with human immunodeficiency virus (HIV) (1). Most patients present with locally advanced disease (2), defined as stages IB2-IVA by the International Federation of Gynaecology and Obstetrics (FIGO), and concurrent chemoradiation remains the standard of treatment for these patients. However, the majority of recurrences occur within two years after treatment $(3,4)$. A defective immune surveillance might contribute to poor outcomes. Theoretically, tumours can evade immune surveillance by upregulating programmed cell death-ligand 1 (PD-L1) expression. PD-L1 is known to play a key role in the inhibition of $\mathrm{T}$ cell-mediated immune responses, leading to the progression of tumours. PD-L1 on malignant cells is often upregulated within the cancer 
microenvironment (5). Several mechanisms contributing to the upregulation of PD-L1 on malignant cells, including epigenetic factors, oncogenic signalling and acquired immune responses, have been identified. Constitutive oncogenic signalling has been discovered to induce PD-L1 expression on malignant cells either through the phosphatidylinositol-3-kinase-protein kinase B (PI3K-AKT) pathway or signal transducer and activator of transcription (STAT) 3 signalling $(6,7)$. In addition, the acquired immune response is considered to manifest through PD-L1 upregulation on malignant cells by endogenous antitumour immunity-related factors in the cancer microenvironment, such as interferon- $\gamma($ IFN- $\gamma)$ produced by tumour-infiltrating lymphocytes (8).

PD-L1 overexpression has been identified in many solid cancer types (9), such as malignant melanoma (10), pulmonary cancer (11) and colorectal cancer (12). Wu et al (9) demonstrated that PD-L1 overexpression is related to worse overall survival in gastric carcinoma, hepatocellular carcinoma, oesophageal carcinoma, and transitional cell carcinoma, whereas this relationship is not present in pulmonary cancer and malignant melanoma.

Interestingly, amplification of chromosome 9p24.1 has recently been demonstrated as an essential mechanism for increased PD-L1 protein expression in nodular sclerosing classical Hodgkin lymphoma and primary mediastinal large B-cell lymphoma (13). Consequently, 9p24.1 gene locus amplification has been discovered in subsets of colorectal carcinoma, triple-negative breast cancer, glioblastoma and gastric adenocarcinoma $(14,15)$.

More recently, the genetic basis of increased PD-L1 expression was identified in cervical and vulvar squamous cell carcinoma. The genes encoding PD-L1 and PD-L2, $C D 274$ and $P D C D 1 L G 2$, respectively, were coamplified or overexpressed due to chromosomal gains in $67 \%$ of cervical and $43 \%$ of vulvar squamous cell carcinoma cases assessed by fluorescence in situ hybridization (FISH) (16). The data show that 9 p24.1 gene copy number alterations are an important mechanism of increased PD-L1 expression in cervical squamous cell carcinoma. However, this study did not investigate the correlation of genetic changes with clinical outcomes.

In the highly active antiretroviral therapy era, several studies have demonstrated that the incidence of AIDS-defining cancer among HIV-positive patients has significantly decreased over the past few decades (17-19). Regarding cervical cancer, a recent meta-analysis showed a reduction in the incidence and progression of cervical intraepithelial neoplasia and the incidence of invasive cervical cancer after antiretroviral therapy (ART) (20). However, the interactions between ART and high-risk human papillomavirus (HPV) and invasive cervical cancer in HIV-positive patients are poorly understood. Several previous studies have shown that ART possesses anti-HPV and anticancer properties in addition to improving functional immunity (21).

Several antitumour mechanisms have been discovered, including inhibition of angiogenesis, invasion of cancer cells and induction of apoptosis (21). Consequently, ART might hold promise for treating cancer. Furthermore, it is possible that ART might participate in a variety of anticancer mechanisms and associate with PD-L1 expression via the downregulation of common signalling pathways or cytokines. Hence, we aimed to explore this relationship using PD-L1, a prognostic and predictive biomarker in various solid tumours. The associations of ART, PD-L1 protein expression, and PD-L1 gene copy number status with clinical outcomes were studied by comparing ART-exposed subjects with ART-unexposed controls.

\section{Materials and methods}

Patients. The retrospective cohort consisted of 48 HIV-infected patients and 123 uninfected controls with International Federation of Gynaecology and Obstetrics stage (FIGO) stage IB2-IVA cervical cancer who underwent tissue biopsies of squamous cell carcinoma and adenocarcinoma of the cervix between December 2008 and December 2016 at the Faculty of Medicine, Navamindradhiraj University, the National Cancer Institute, and Rajavithi Hospital. The present study was approved by the Institutional Review Boards of Navamindradhiraj University, the National Cancer Institute, and Rajavithi Hospital. All patients provided informed consent. $\mathrm{H} \& \mathrm{E}$-stained sections were reviewed by two pathologists (KL and NP). Complete clinicopathologic data were available for all patients. The inclusion and exclusion criteria are described below.

Inclusion criteria: Subjects were eligible if they i) had stage IB2-IVA cervical cancer; ii) were HIV-positive and had previously been exposed to ART more than one year before the diagnosis of cervical cancer (classified as the ART-exposed group); and iii) were HIV-positive and had never been exposed to ART before cervical cancer diagnosis (classified as the ART-untreated group).

Exclusion criteria: Subjects were excluded from the study for the following reasons: i) Previous exposure to chemoradiation therapy before cervical cancer diagnosis; ii) known history of the following underlying illnesses (autoimmune diseases, diabetes mellitus, and hepatitis $\mathrm{B}$ or $\mathrm{C}$ virus coinfection); iii) taking immunosuppressive or antituberculous drugs within one year before the diagnosis of cervical cancer; and iv) presence of synchronous or metachronous malignancy.

Immunohistochemistry. Immunohistochemistry (IHC) was performed in all cases with a monoclonal antibody recognizing PD-L1. Whole tissue sections $(4 \mu \mathrm{m})$ were cut and stained for PD-L1 (clone SP263; Ventana Medical Systems, Inc.) on an automated staining platform (Benchmark ULTRA; Ventana Medical Systems, Inc.). An OptiView DAB IHC Detection Kit (Ventana Medical Systems, Inc.) was used according to the manufacturer's instructions for the visualization of the primary anti-PD-L1 antibody. Human placental tissue was used as a positive control in all immunohistochemical reactions. Immunohistochemical expression of PD-L1 in malignant cells was evaluated by counting the proportion of positive malignant cells and quantifying IHC staining intensity in a 4-tiered scoring system according to Hofmann's criteria (22) as follows: Score 0 indicated no appreciable staining or staining in less than $10 \%$ of malignant cells; score 1+ indicated weak appreciable partial membranous staining in $>10 \%$ of malignant cells; score $2+$ indicated moderate complete membrane staining in $>10 \%$ of malignant cells; and score $3+$ indicated intense complete membrane staining in $>10 \%$ of malignant 
cells. Based on a previous study involving other malignancies (23), tumours with $5 \%$ or more cells showing positive PD-L1 staining, regardless of the intensity, were considered 'positive'.

For p16 IHC, 4- $\mu$ m tissue microarray (TMA) sections were cut from formalin-fixed paraffin-embedded tissue, and IHC was performed on a Leica Bondmax platform (Leica Micro-systems) according to the manufacturer's instructions. Mouse monoclonal anti-p16 (clone JC8, 1:600 dilution; Santa Cruz Biotechnology) was used as a primary antibody. p16 IHC was scored as positive if there was strong and diffuse nuclear and cytoplasmic staining present in greater than $70 \%$ of malignant cells.

PD-L1 fluorescence in situ hybridization. Tissue microarrays (TMAs) with $3 \mathrm{~mm}$ core diameter were obtained from representative cervical cancer tissues. Dual-colour FISH analysis was performed on $4 \mu \mathrm{m}$ FFPE TMA sections. The SPEC CD274, PDCD1LG2/CEN9 Dual Color Probe (Zytovision) was used according to the manufacturer's guidelines.

At least 50 malignant cells were detected based on DAPI-stained nuclei. PD-L1 amplification was defined as a PD-L1/CEP9 ratio $\geq 2.0$. Polysomy was defined as a mean copy number of PD-L1 $\geq 3.0$, with a PD-L1/CEP9 ratio $<2.0$. All other instances were considered disomy as previously reported (24).

Statistical analysis. Statistical analysis was performed using Stata Statistical Software (College Station, TX: StataCorp LP; http://www.stata.com). The distribution of qualitative data was compared between groups using $\chi^{2}$ tests or Fisher's exact tests, depending on the cell counts of corresponding contingency tables. For survival analysis, the Kaplan-Meier method was used to compute recurrence-free survival (RFS), cancer-specific survival (CSS), and locoregional recurrence-free survival (LRR). Univariate and multivariate analyses were performed using Cox proportional hazards models, and the differences between groups were analysed using the log-rank test. For all statistical analyses, $\mathrm{P}<0.05$ was considered statistically significant.

\section{Results}

Patient Characteristics. The clinicopathological characteristics of the cervical cancer patients in the HIV-positive or HIV-negative cohorts are shown in Table I. The median follow-up time was 40 (range: 1-120) months for the HIV-positive cohort and 28 (range: 2-82) months for the HIV-negative cohort. The median CD4 count was 312 (interquartile range (IQR): 158.5-439.0). Among the HIV-positive patients $(n=48)$, there was no significant difference in the mean age of ART-exposed patients $(n=23)$ and ART-untreated patients $(\mathrm{n}=25)$ [43.70 (9.07) vs. $40.68(9.83)$ years; $\mathrm{P}=0.276$ ]. The median time on ART was 21 (range: 12.5-91) months. Compared to ART-untreated patients, ART-exposed patients $(\mathrm{n}=23)$ usually had FIGO stage IB2-IIB disease (82.6 vs. 48.0\%; $\mathrm{P}=0.012)$, increased CD4 counts (74.0 vs. $40.0 \% ; \mathrm{P}=0.022)$, undetectable viral loads ( 82.6 vs. $40.0 \% ; \mathrm{P}=0.003$ ), reduced tumour sizes ( 34.8 vs. $4.0 \%$; $\mathrm{P}=0.009)$ and reduced likelihood of having parametrial invasion (52.2 vs. $92.0 \%$; $\mathrm{P}=0.002)$.
There were no differences in the histologic subtypes of squamous cell carcinoma (73.9 vs. $92.0 \% ; \mathrm{P}=0.130)$, presence of metastatic lymph nodes (30.4 vs. $36.0 \%$; $\mathrm{P}=0.683$ ) or use of radio (chemo) therapy (100.0 vs. $96.0 \% ; \mathrm{P}=1.000)$ between the two groups. No significant correlation was observed between the NRTI+NNRTI group and the NRTI+PI group with regard to patient age [40.69 (10.14) vs. 41.43 (5.97) years; $\mathrm{P}=0.441]$, higher $\mathrm{CD} 4$ counts $(75.0$ vs. $71.4 \% ; \mathrm{P}=1.000)$, undetectable viral loads (81.2 vs. $85.7 \%$; $\mathrm{P}=1.000)$, FIGO stage 1B2-IIB disease (81.3 vs. $85.7 \% ; \mathrm{P}=1.000)$, tumour size $\geq 4 \mathrm{~cm}$ ( 75.0 vs. $42.9 \%$; $\mathrm{P}=0.182$ ), the presence of parametrial invasion (75.0 vs. $71.4 \%$; $\mathrm{P}=1.000)$, histologic subtype of squamous cell carcinoma ( 68.8 vs. $85.7 \%$; $\mathrm{P}=0.621$ ), or the presence of metastatic nodes (37.3\%; $\mathrm{P}=0.366)$. Additionally, ART-exposed patients had younger age [median age, 43.70 (9.07) vs. 55.15 (12.67) years; $\mathrm{P}<0.001]$, more likelihood of FIGO stage IB2-IIB disease (82.6 vs. 62.6\%; $\mathrm{P}=0.063$ ), and lower prevalence of parametrial invasion (52.2 vs. 79.7\%; $\mathrm{P}=0.005)$ than $\mathrm{HIV}$-negative patients $(n=123)$. No other correlations were observed between the two groups.

Status of PD-L1 expression. For the entire cohort, PD-L1 expression in at least $5 \%$ of tumour cells was identified in $130 / 171(76 \%)$ of cervical carcinoma cases. The mean percentage of positive tumour cells (any intensity of staining) was $60 \%$ (range: $15-90 \%$ ). Strong membranous staining (3+) was identified in $24 / 171$ (14\%) cases, moderate staining (2+) in 46/171 (27\%) cases, and weak staining (+1) in 39/171 (23\%) cases (Fig. 1). Fig. 3 shows the proportion of PD-L1 immunoreactivity in each patient group. There was a significant difference in PD-L1 overexpression between the HIV-positive cohort and HIV-negative cohort (56.3 vs. 83.7\%; $\mathrm{P}<0.001)$. Among the HIV-positive patients, compared to ART-untreated patients, ART-exposed patients showed a significant decrease in PD-L1 protein expression (26.1 vs. 84\%; $\mathrm{P}<0.001)$. Additionally, ART-exposed patients had a lower prevalence of PD-L1 immunopositivity than HIV-negative patients (26.1 vs. 83.7\%; $\mathrm{P}<0.001$ ).

Status of p16 expression. P16 positivity was not altered by the HIV status, ART use, or antiretroviral drug regimen. All cases in the HIV cohort displayed p16 immunopositivity, whereas nearly all cases in the HIV-negative cohort were p16-positive except for two cases of adenocarcinoma. No significant correlation was observed in any of the groups with regard to any of the relevant parameters mentioned above (data not shown).

Status of PD-L1 gene copy number alterations. Overall, $12 / 171(7 \%)$ tumours were positive for amplification. Gene copy number gain was restricted to tumour cells and was not present in the inflammatory cell component. Polysomy was observed in 60/171 (35\%) cases. A total of 99/171 (58\%) cases were disomic for the PD-L1 gene locus at 9p24.1 (Fig. 2). Fig. 3 shows the proportion of PD-L1 copy number alterations in each patient group. There was no significant difference in PD-L1 amplification, polysomy, or disomy (64.6 vs. 55.3\%, 27.1 vs. $38.2 \%$ and 8.3 vs. $6.5 \%$, respectively; $\mathrm{P}=0.387$ ) between the HIV-positive cohort and the HIV-negative cohort. Among the HIV-positive cohort, ART-exposed patients had a lower prevalence of amplification ( 0 vs. 28.6\%; 


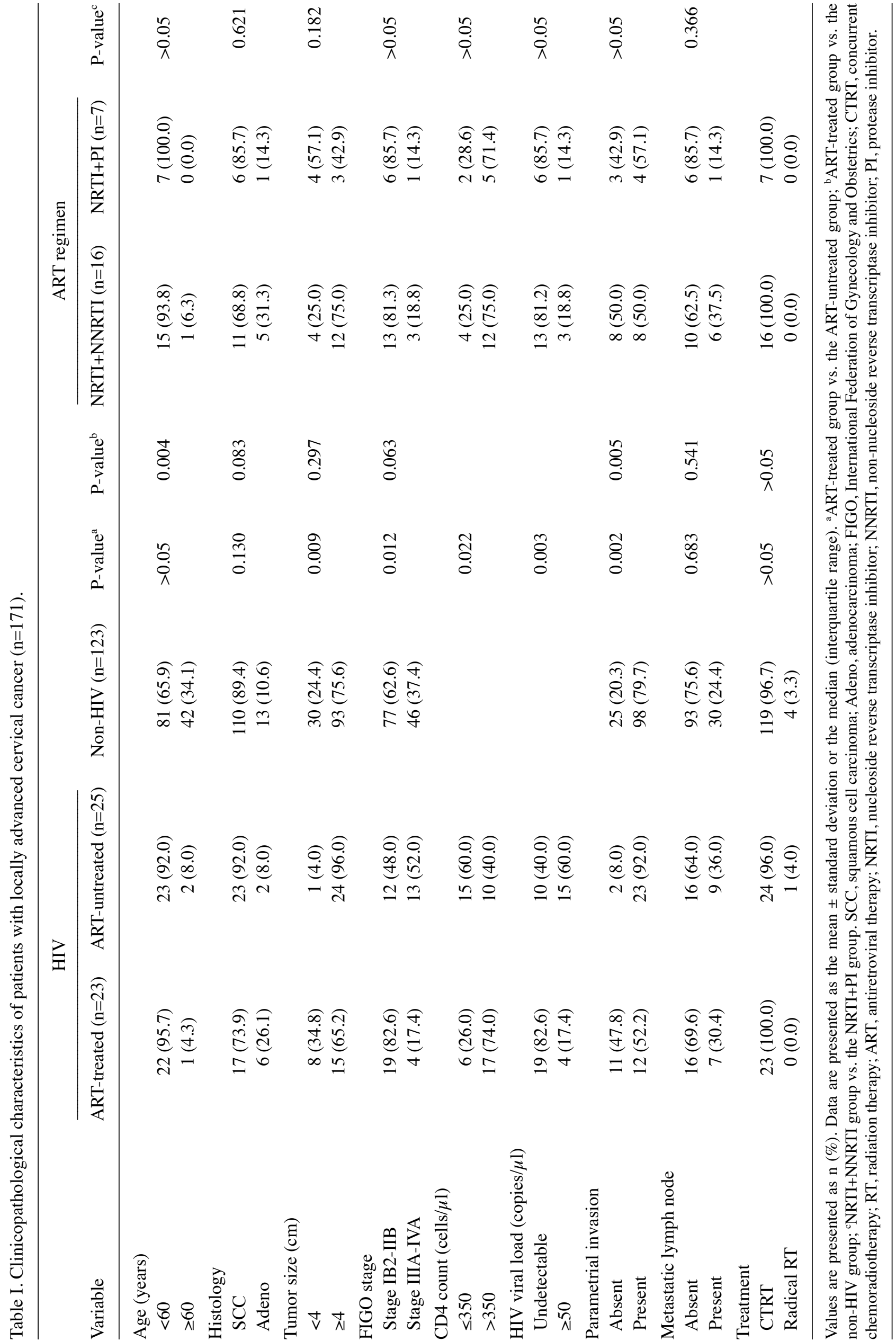


A

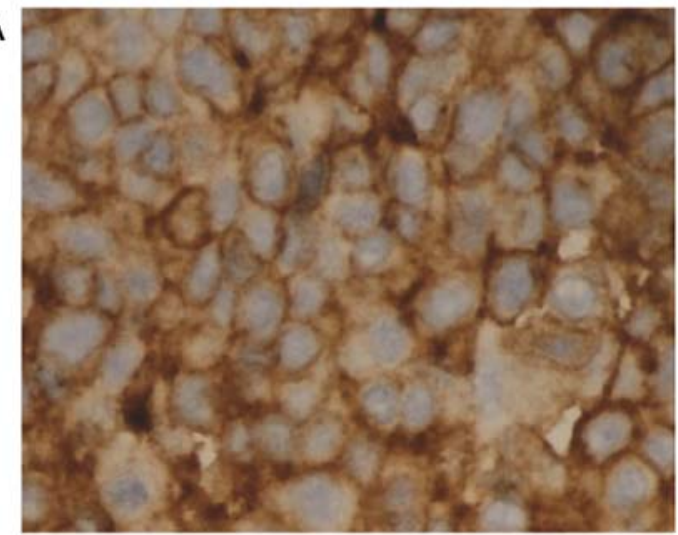

B

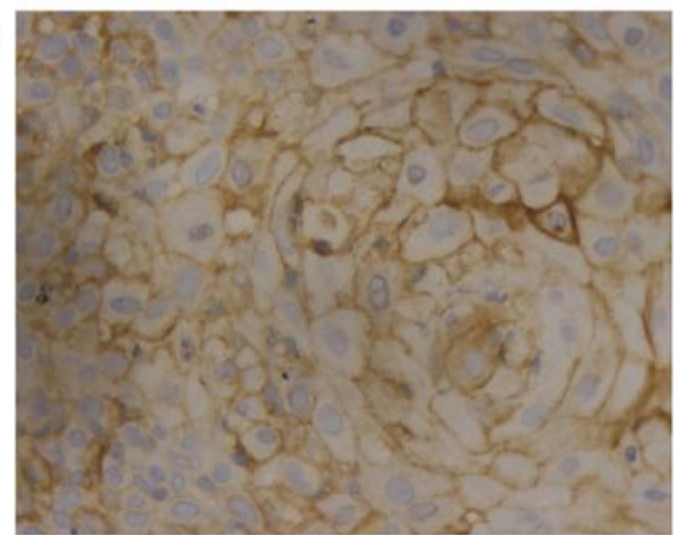

C

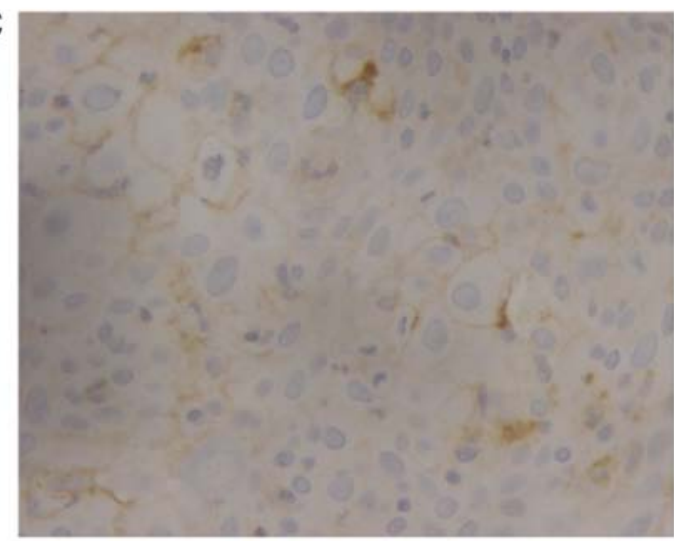

D

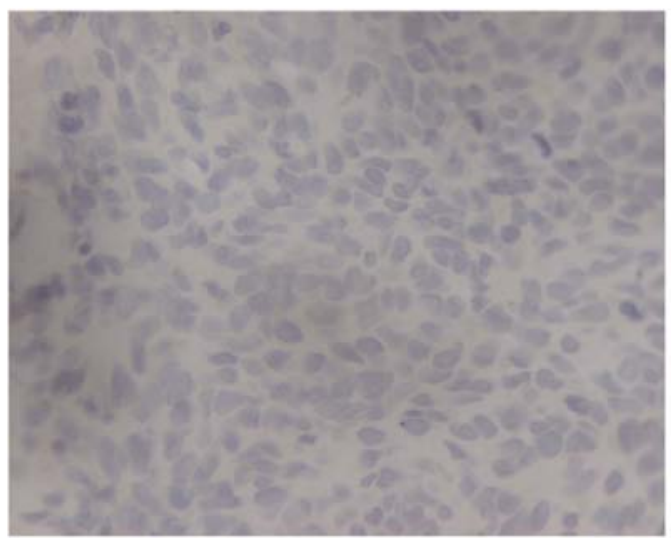

Figure 1. Intensities of PD-L1 immunohistochemical reactions (original magnification, x60). (A) Representative image of 3+ intensity staining, revealing a strong circumferential cell membrane reaction. (B) Representative image of intensity 2+, exhibiting moderate complete circumferential cell membrane staining. (C) Intensity 1+, presenting weak appreciable partial cell membrane staining and (D) intensity 0, presenting no cell membrane reaction. PD-L1, programmed cell death-ligand 1 .

$\mathrm{P}=0.019)$ and polysomy (8.7 vs. 52.4\%; $\mathrm{P}=0.002)$ and a higher prevalence of disomy (91.3 vs. $40 \%$; $\mathrm{P}<0.001)$ than their ART-untreated counterparts. Additionally, ART-exposed patients had a lower prevalence of polysomy (8.7 vs. $40.9 \%$; $\mathrm{P}=0.003)$ and a higher prevalence of disomy (91.3 vs. $55.3 \%$; $\mathrm{P}=0.001)$ than HIV-negative patients. There were no differences in amplification between the two groups (0 vs. 10.5\%; $\mathrm{P}=0.195)$.

Correlation between PD-L1 copy number gain and PD-L1 protein expression. Results for both PD-L1 immunohistochemistry and PD-L1 FISH are shown in Table II. Tumours with PD-L1 gene amplification and polysomy displayed membranous PD-L1 immunostaining (scores $1+$ to $3+$ ) by immunohistochemistry in 11/12 (92\%) and 46/60 (76\%) cases, respectively. A significantly higher frequency of cases with PD-L1 amplification were PD-L1 immunopositive than cases without amplification (92 vs. 61.6\%; $\mathrm{P}=0.03$ ). Likewise, the proportion of PD-L1 immunopositive tumours with PD-L1 polysomy were significantly higher than those of tumours with disomy (76.7 vs. $52.5 \%$; $\mathrm{P}=0.002$ ). Furthermore, $7 / 12$ carcinoma cases with strong membranous PD-L1 immunostaining (score 3+) showed PD-L1 amplification, 11/60 showed a polysomy, and 6/99 cases displayed a disomy.

Survival outcomes. Fig. 4 shows the Kaplan-Meier survival curves for exposed (ART-exposed) vs. unexposed ART
(ART-untreated and HIV-negative) patients, according to the IHC-based and FISH-based expression status of PD-L1 in tumours. Overall, ART-exposed patients had longer survival with regard to LRR, RFS, and CSS than ART-unexposed patients. The results of univariate and multivariate analyses evaluating the impact of various known prognostic factors on LRR, RFS and CSS are summarized in Table III (Tables SI-III).

For the entire cohort, FIGO stage (HR, 2.87; 95\% CI, 1.76-4.69; $\mathrm{P}<0.001$ vs. HR, 14.73; 95\% CI, 6.18-35.09; $\mathrm{P}<0.001)$, tumour size (HR, 2.30; 95\% CI, 1.17-4.52; $\mathrm{P}=0.016$ vs. HR, 6.79; 95\% CI, 1.64-28.08; $\mathrm{P}=0.008)$, nodal status (HR, 1.98; 95\% CI, 1.20-3.27; P=0.007 vs. HR, 2.19; 95\% CI, 1.19-4.03; $\mathrm{P}=0.012)$, PD-L1 amplification (HR, 8.37; 95\% CI, 3.67-19.12; $\mathrm{P}<0.001$ vs. HR, 7.46; 95\% CI, 3.15-17.69; $\mathrm{P}<0.001)$ and polysomy (HR, 2.39; 95\% CI, 1.44-3.99; P=0.001 vs. HR, 2.08; 95\% CI, 1.07-4.05; $\mathrm{P}=0.031)$ were univariately associated with RFS and CSS. Nevertheless, on multivariate analysis, FIGO stage and PD-L1 amplification continued to show a significant impact on RFS (HR, 2.43; 95\% CI, 1.37-4.30; $\mathrm{P}=0.002$ vs. $\mathrm{HR}, 7.03$; 95\% CI, 2.79-17.74; $\mathrm{P}<0.001)$ and $\mathrm{CSS}$ (HR, 11.47; 95\% CI, 4.70-27.99; $\mathrm{P}<0.001$ vs. HR, 4.05; 95\% CI, 1.64-9.98; $\mathrm{P}=0.002)$. FIGO stage and $\mathrm{PD}-\mathrm{L} 1$ polysomy showed a significant impact on LRR in univariate analysis (HR, 2.55; 95\% CI, 1.23-5.28; $\mathrm{P}=0.012$ vs. HR, 3.46; 95\% CI, 1.61-7.45; $\mathrm{P}=0.002)$; however, only $\mathrm{PD}-\mathrm{L} 1$ polysomy remained an independent predictor of LRR in the multivariate analysis (HR, 2.50; 95\% CI, 1.11-5.63; $\mathrm{P}=0.027)$. In subgroup analyses, 

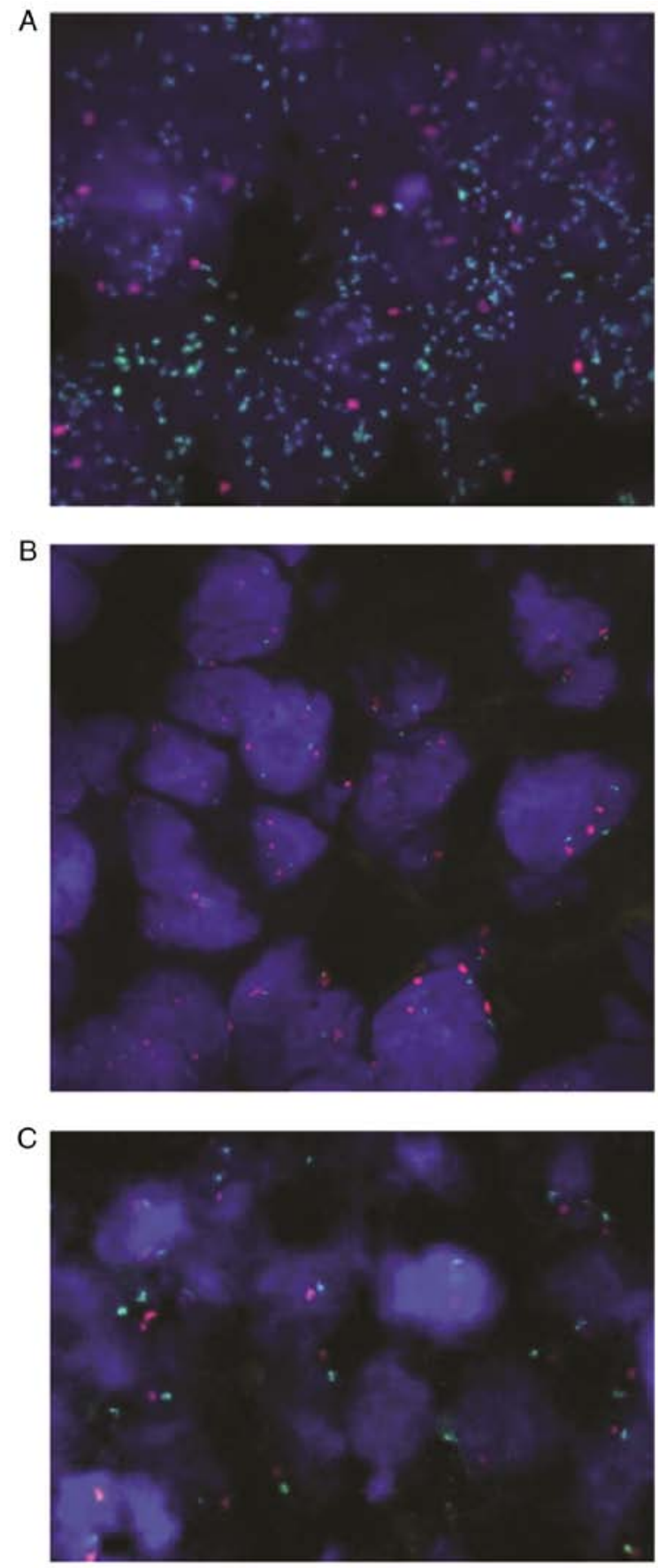

Figure 2. FISH analysis of the PD-L1 gene locus. (A) Amplification of the PD-L1 gene locus, (B) PD-L1 polysomy and (C) PD-L1 disomy. Green indicates the PD-L1 gene and red indicates centromere 9. FISH, fluorescence in situ hybridization; PD-L1, programmed cell death ligand 1.

ART exposure was univariately correlated with CSS (HR, $0.21 ; 95 \% \mathrm{CI}, 0.04-0.96 ; \mathrm{P}=0.044)$ in the HIV-positive cohort; however, no significant difference was observed in the multivariate analysis (HR, 0.55; 95\% CI, 0.12-2.63; $\mathrm{P}=0.455$ ).

There was no significant difference in LRR, RFS, or CSS between the ART-exposed group and the HIV-negative group (HR, 0.26; 95\% CI, 0.03-1.94; $\mathrm{P}=0.187$, HR, 0.60; 95\% CI, 0.24-1.47; $\mathrm{P}=0.265$, and HR, $0.50 ; 95 \% \mathrm{CI}, 0.12-2.20 ; \mathrm{P}=0.362$, respectively) or between the ART-untreated group and the HIV-negative group (HR, 0.95; 95\% CI, 0.36-2.5; $\mathrm{P}=0.913$, $\mathrm{HR}, 1.07$; 95\% CI, 0.55-2.09; $\mathrm{P}=0.833$, and HR, 1.09; 95\% CI,
0.49-2.42; $\mathrm{P}=0.826$, respectively) on multivariate analysis. The data demonstrated that HIV status was not associated with worse outcomes in Cox models.

\section{Discussion}

In the present study, our results showed an association between ART and PD-L1 expression. We found that ART-exposed patients had a significantly lower prevalence of PD-L1 protein expression, PD-L1 amplification and polysomy, and better clinical outcomes than ART-untreated HIV-positive and HIV-negative patients. As reported in earlier studies (25), HIV-positive women tended to have aggressive cervical cancer with a poor prognosis. Nevertheless, a recent analysis of surveillance data pertaining to the post-antiretroviral era showed a comparable prognosis for HIV-positive and HIV-negative populations (18). Although several factors that contribute to poor prognosis of cervical cancer in HIV-positive patients have been proposed, the definite aetiology in this respect has not been clearly identified. From the standpoint of anticancer immunity, suppression of the T cell-mediated anticancer immune response is likely to underlie the association between HIV infection and poor prognosis for cervical cancer.

In addition to improving functional immunity, ART could exert a combined effect on oncogenic HPV infection and cervical cancer. Different antiretroviral drug combinations may show a wide spectrum of activity and improved potency (i.e., synergistic or additive effects) against HPV infection or cancer cells. In a recent meta-analysis, Kelly et al demonstrated that ART may reduce the risk for cervical cancer and its precursor lesions in women living with HIV (20). Interestingly, these effects remained after adjusting for immune restoration indicators, such as CD4 cell count and duration of ART use.

In vitro studies have shown that lopinavir in some ART regimens may have activity against oncogenic HPV through the inhibition of the viral oncogene E6 (26). Several studies have shown that protease inhibitors (PIs) and other anti-HIV drugs possess several pleiotropic anticancer properties, including inhibition of cancer cell invasion, angiogenesis, inflammatory cytokine production, and proliferation and induction of apoptosis $(21,27)$. Several intracellular signalling pathways have been identified, and some of these pathways might be linked to PD-L1 expression.

An in vitro study in cultured squamous cell carcinoma of the head and neck (SCCHN) cell lines demonstrated that PD-L1 expression is significantly upregulated in response to interferon- $\gamma$ (IFN- $\gamma$ ), a key cytokine triggering de novo PD-L1 induction in tumour cells and normal tissues (28).

PD-L1 expression can be stimulated by autocrine/paracrine mediators within the cancer microenvironment, especially IFN- $\gamma$. Interactions between extrinsic stimuli and the IFN- $\gamma$ receptor could lead to the expression and activation of various downstream signalling pathways, including nuclear factor- $\kappa$ light chain enhancer of activated B cells (NF- $\mathrm{KB}$ ), mitogen-activated protein kinase (MAPK), phosphoinositide 3-kinase (PI3K), mammalian target of rapamycin (mTOR) and Janus kinase/signal transducer and activator of transcription (JAK/STAT), which promote cell cycle progression and the activation of transcription factors. Such signalling pathways 
Table II. PD-L1 FISH and PD-L1 IHC.

\begin{tabular}{lccccc}
\hline PD-L1 FISH & $\begin{array}{c}\text { Cases } \\
(\mathrm{n}=171)\end{array}$ & $\begin{array}{c}\text { PD-L1 } \\
\text { IHC Score 3+ }\end{array}$ & $\begin{array}{c}\text { PD-L1 IHC } \\
\text { Score 2+ }\end{array}$ & $\begin{array}{c}\text { PD-L1 IHC } \\
\text { Score 1+ }\end{array}$ & $\begin{array}{c}\text { PD-L1 IHC } \\
\text { Score 0 }\end{array}$ \\
\hline Amplification & $12(7 \%)$ & $7 / 12$ & $2 / 12$ & $2 / 12$ & $1 / 12$ \\
Polysomy & $60(35 \%)$ & $11 / 60$ & $18 / 60$ & $17 / 60$ & $14 / 60$ \\
Disomy & $99(58 \%)$ & $6 / 99$ & $26 / 99$ & $20 / 99$ & $47 / 99$ \\
\hline
\end{tabular}

PD-L1, programmed cell death ligand 1; FISH, fluorescence in situ hybridization; IHC, immunohistochemistry.
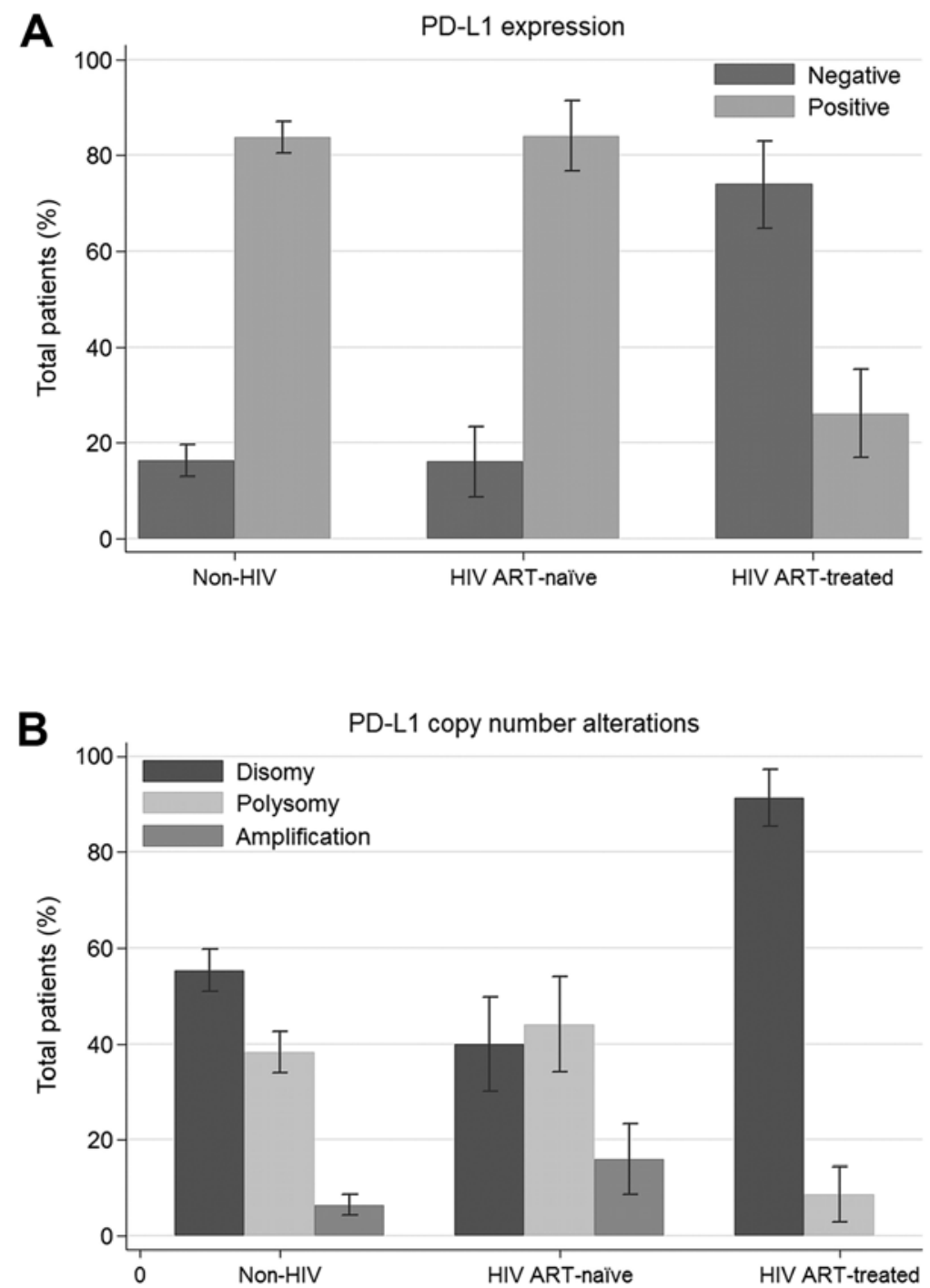

Figure 3. PD-L1 immunoreactivity and PD-L1 copy number alterations in non-HIV patients, ART-naïve patients and ART-treated patients with cervical carcinomas. (A) Percentage of PD-L1 immunoreactivity across patient groups. (B) Percentage of PD-L1 copy number alterations (disomy, polysomy and amplification) across patient groups. Data are presented as the mean \pm standard error of the mean. PD-L1, programmed cell death ligand 1; ART, antiretroviral therapy.

further regulate the nuclear translocation of transcription factors to the PD-L1 promoter (29).

In the setting of HIV infection, several cytokines are produced by infected cells and cells of the immune system. Both innate and adaptive immune responses are activated during the disease course. $\mathrm{CD} 4^{+} \mathrm{T}$ helper cells play a crucial role in the immune system by secreting cytokines that regulate the immune response. Th1 $\mathrm{CD} 4{ }^{+}$subsets produce IL-2 and IFN- $\gamma$. IFN- $\gamma$ acts by stimulating macrophages and is important for eliminating intracellular pathogens (30). Previous studies conducted by De Luca et al documented that the production of various inflammatory cytokines [macrophage inflammatory protein- $1 \alpha$ (MIP-1 $\alpha$ ), macrophage inflammatory protein-1 $\beta$ (MIP-1 $\beta$ ), regulated on activation, normal $\mathrm{T}$ cell expressed and secreted (RANTES), and IFN- $\gamma]$ can be significantly inhibited at 8 weeks and partially recovered at 24 weeks after the commencement of 
A

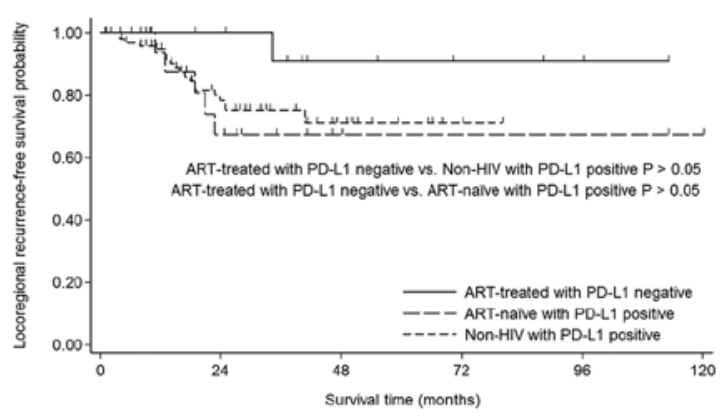

C

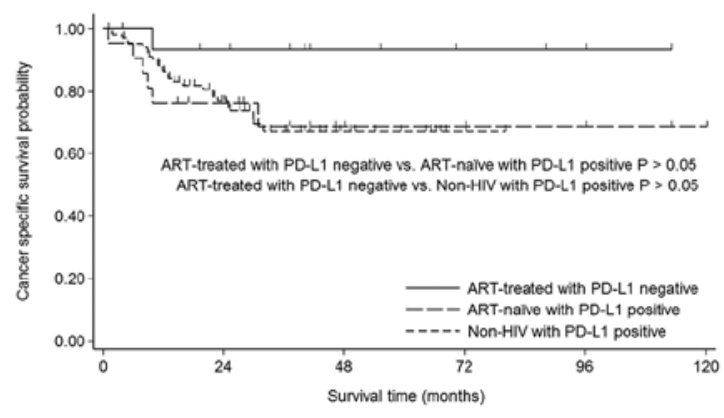

E

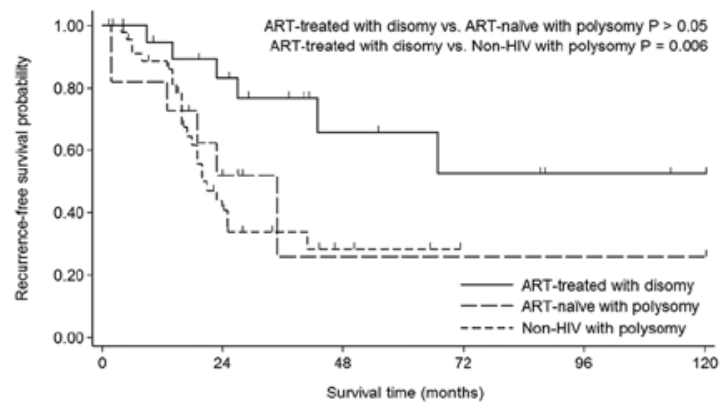

G

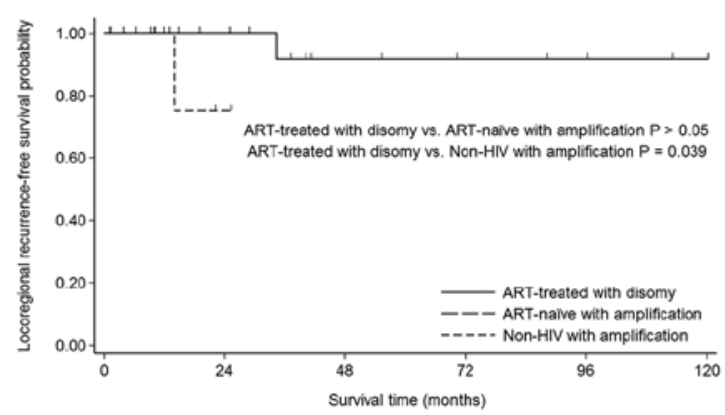

B

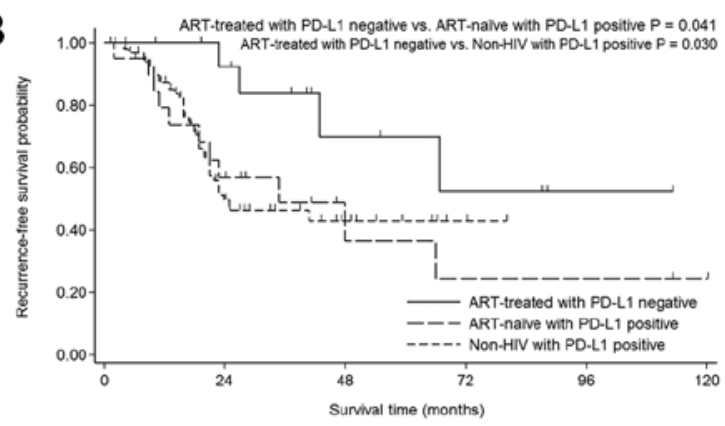

D

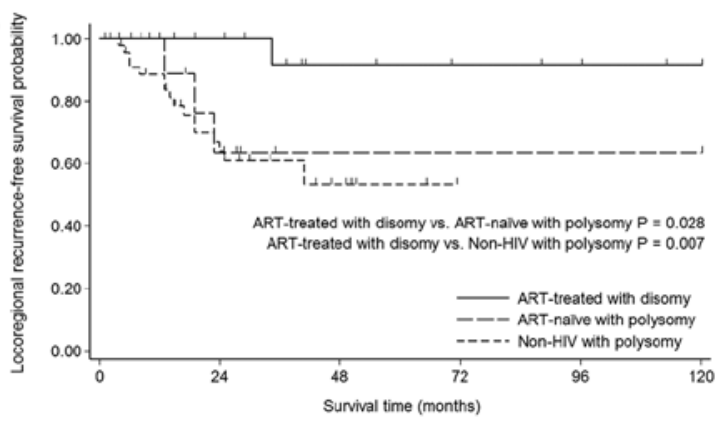

$\mathbf{F}$

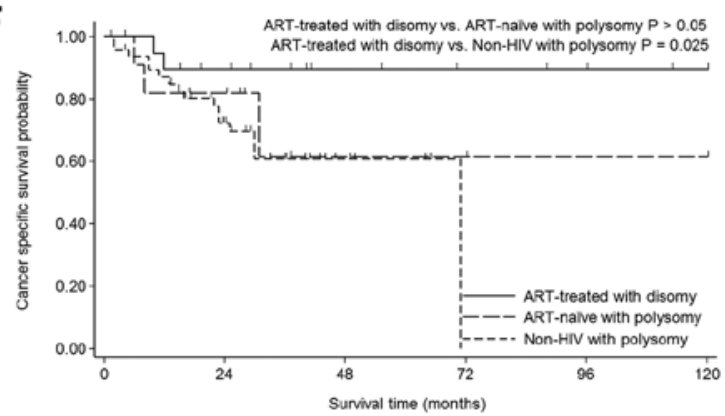

H

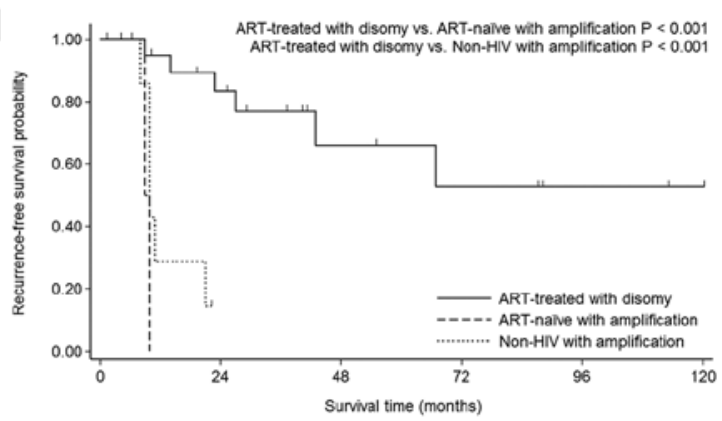

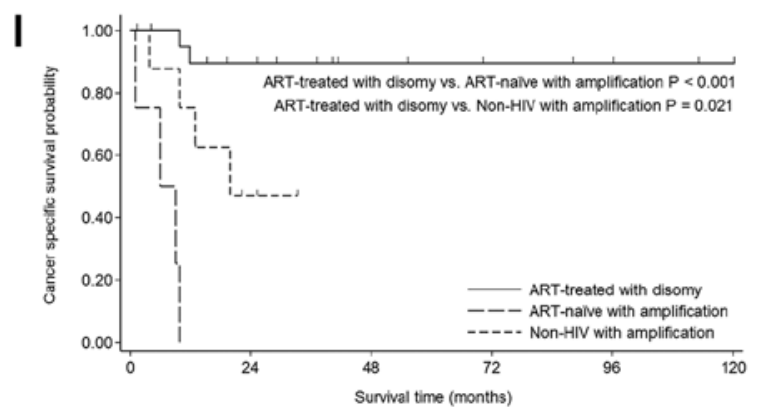

Figure 4. Kaplan-Meier survival curves for exposed vs. unexposed ART patients in relation to PD-L1 immunoreactivity and genetic category. (A) LRR (B) RFS, and (C) CSS based on exposed ART patients that are PD-L1 negative vs. unexposed ART patients that are PD-L1 positive. (D) LRR, (E) RFS and (F) CSS based on exposed ART patients with disomy vs. unexposed ART patients with polysomy. (G) LRR, (H) RFS and (I) CSS based on exposed ART patients with disomy vs. unexposed ART patients with amplification. ART, antiretroviral therapy; PD-L1 programmed cell death ligand 1; LRR, locoregional recurrence-free survival; RFS, recurrence-free survival; CSS, cancer-specific survival. 


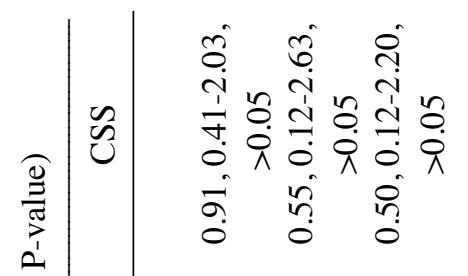

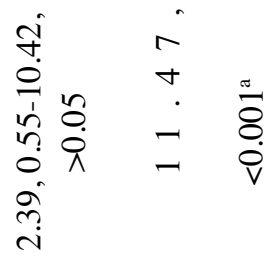

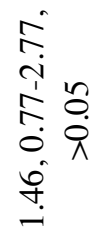

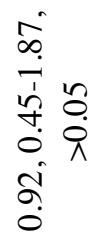

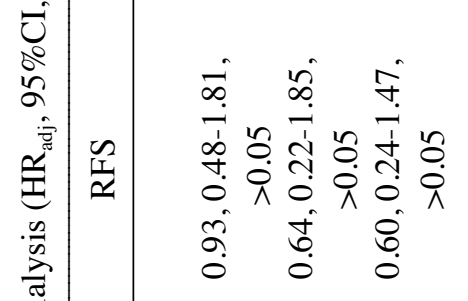

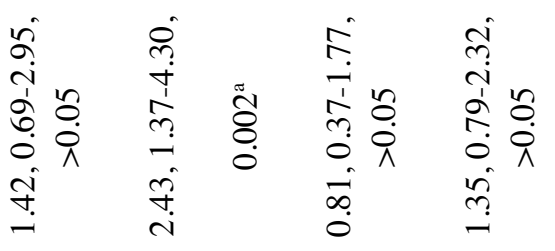

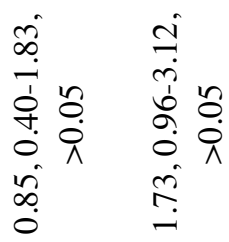

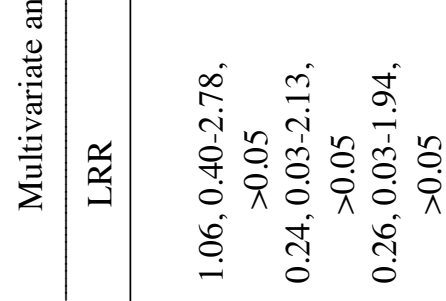

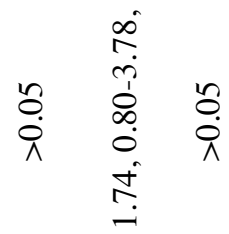

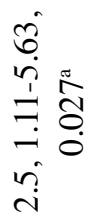

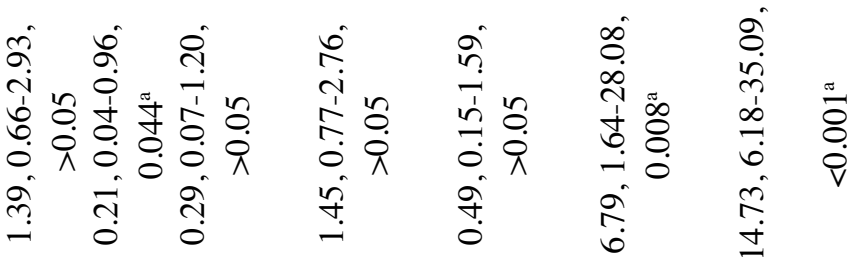

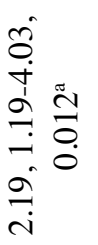

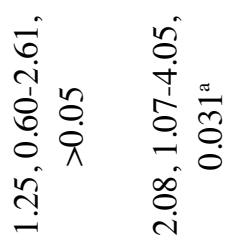

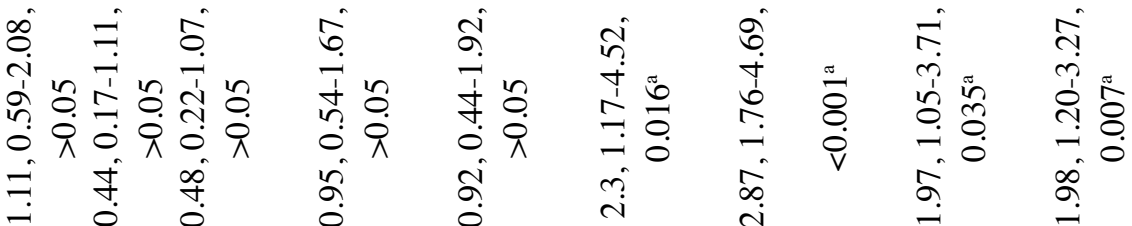

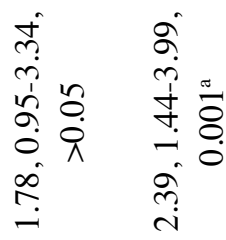

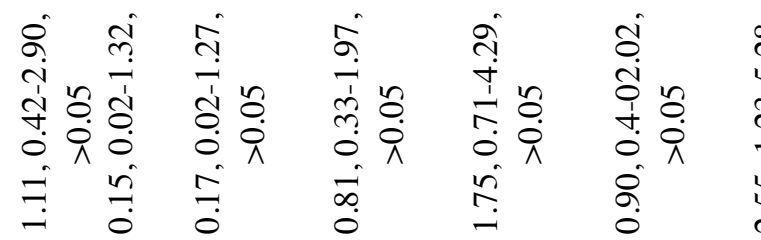

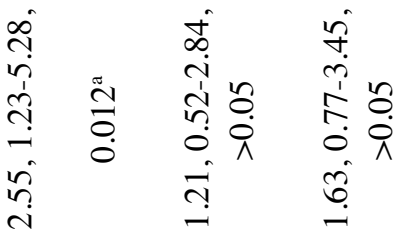

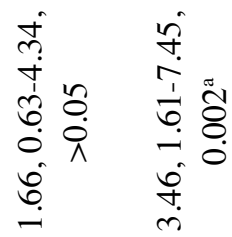

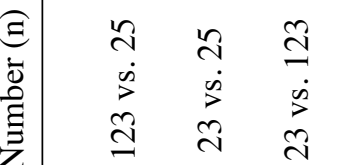

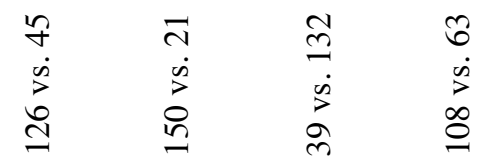

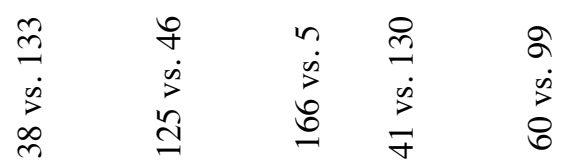

की

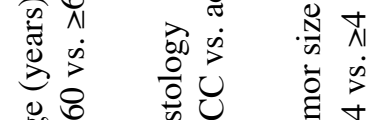

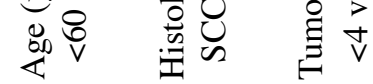

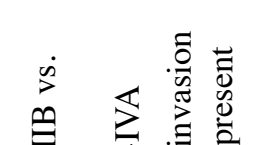

$\frac{\pi}{0}$

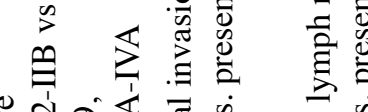

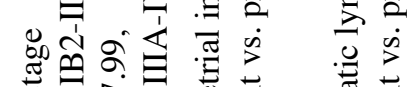

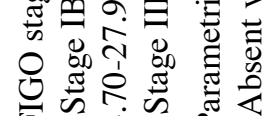
莺

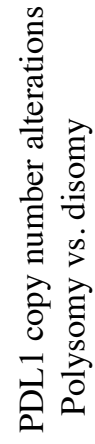


protease inhibitor therapy in patients with advanced HIV infection (31).

In cross-sectional and longitudinal clinical studies, comparison of ART-untreated to ART-exposed subjects demonstrated high serum levels of many cytokines, which were significantly reduced when ART was initiated. A cross-sectional study of pre- and post-ART showed lower serum levels of IFN- $\gamma$ with the initiation of ART (32). A longitudinal study displayed a statistically significant reduction in IFN- $\gamma$ after ART for 60 days or longer. In addition, a study conducted by Piconi et al found that different NRTI combinations (AZT+ddI and AZT+3TC) could exert different effects on IFN- $\gamma$ and interleukin-2 (IL-2) production (33).

Nevertheless, IFN- $\gamma$-induced PD-L1 expression can fluctuate at different time points during the disease course. In contrast, PD-L1 expression can be continuously activated via gene amplification events involving a gene locus on chromosome 9p24.1. The additional somatic copy number alterations resulting in an increase in the fraction of DNA regions could be associated with carcinogenesis and cancer progression. Several important genes are known to be amplified and have been identified as prognostic markers, factors associated with drug resistance, or treatment targets in some cancer types, such as non-small cell lung cancer (34).

The 9p24.1 chromosomal region contains the genes encoding PD-L1, PD-L2 and JAK2.

Amplification of the chromosomal region 9p24.1 has recently been demonstrated as an essential mechanism for increased PD-L1 protein expression in nodular sclerosing classical Hodgkin lymphoma and primary mediastinal large B-cell lymphoma (13) and has also been identified in colorectal carcinoma, triple-negative breast cancer, glioblastoma and gastric adenocarcinoma (14,15), and cervical and vulvar carcinoma (16).

In the present study, our results demonstrated that PD-L1 copy number gains (amplification and polysomy) can be observed in a subset of cervical cancer patients using FISH analysis (35.4\% for HIV-positive patients and $44.7 \%$ for HIV-negative patients).

In contrast to the results of a previous study (16), our results showed that PD-L1 amplification can be identified in only a minority of cases ( $8.3 \%$ for HIV-positive patients and $6.5 \%$ for HIV-negative patients). These conflicting results can be explained by differences in sample size, disease stage, or underlying diseases in the studied population.

More importantly, we found that ART was correlated with PD-L1 copy number status in addition to protein expression. In the present study, we demonstrated a novel genetic association between PD-L1 copy number gain and ART in cervical carcinoma. However, the exact molecular mechanism for this phenomenon is still unknown.

Based on previous genetic studies, several signalling pathways might be downregulated after treatment with ART, which may lead to a decrease in PD-L1 expression $(35,36)$. The results showed that a variety of genes are downregulated following ART and that these genes might share common pathways with PD-L1, such as the NF-kB, MAPK, and JAK/STAT pathways $(35,36)$. Moreover, several ART-responsive genes have been identified, and the biological processes and functions of a large number of these genes are still unknown (35). The expression of some of these genes could be changed as a 
direct consequence of exposure of human cells to ART, rather than as a consequence of ART-mediated viral suppression (35). Further studies are needed to clarify the relationship between ART and PD-L1 gene expression.

Considering survival outcomes, we found that both copy number gains in the PD-L1 gene and PD-L1 overexpression indicated poor prognosis in univariate analysis. However, PD-L1 copy number gains were superior to PD-L1 overexpression and could act as independent and strong predictors of survival outcomes in cervical carcinoma.

Our results may identify a new subgroup of cervical cancer with a disease-specific genetic alteration. Further studies are required to evaluate the impact of PD-L1 copy number gain on pathogenesis, disease progression and prognosis in this newly identified subgroup of cervical cancer patients. In addition, the identification of PD-L1 gene copy number gain as a powerful mechanism for PD-L1 expression in the present study may provide a rationale for the treatment of cervical cancer patients in this subgroup.

In addition to the abovementioned mechanisms, ART could affect the response to radiation, as some PIs potently sensitize cancer cells to radiation (37). In vitro results have demonstrated that the commonly used combination of tenofovir, emtricitabine, and efavirenz sensitizes tumours to external beam radiation therapy (EBRT) ( $<4$ Gy per fraction) but protects tumours from brachytherapy ( $\geq 4$ Gy per fraction) (38).

In conclusion, although the immunotherapeutic drug pembrolizumab has been approved for locally advanced cervical cancer, the cost of cancer treatment is relatively high, and the response to pembrolizumab alone remains low. In addition to immune-checkpoint inhibitors, various therapeutic options, such as HPV vaccines and adoptive T-cell therapy, are currently being developed for the treatment of cervical cancer (39). However, the development of new drug treatments is both time-consuming and expensive. Subsequently, the repositioning of previously approved drugs for alternative purposes, such as cancer treatment, is reasonable. Hopefully, our preliminary data will be useful and lead to new treatment options for these patients in the future.

\section{Acknowledgements}

The authors would like to thank Ms. Sujitra Tanvanich, Mrs. Unaporn Sitthivilai and Mrs. Pornpimon Kongjan (Department of Anatomical Pathology, Navamindradhiraj University) for theoretical guidance and writing assistance during the present study. The authors would also like to thank Dr Totsapon Jiamton (Department of Obstetrics and Gynecology, Navamindradhiraj University) and Dr Wanniga Saengsuri (Division of Gynecologic Oncology, Taksin Hospital) for clinical advice during the present study. Finally, the authors would like to thank Ms. Oraphan Wanacharoen (BCC MDx Co., Ltd.) for her technical assistance.

\section{Funding}

The current study was supported by a grant from the Faculty of Medicine of Navamindradhiraj University (Bangkok, Thailand; grant no. 12461).

\section{Availability of data and materials}

All data generated or analyzed during this study are included in this published article.

\section{Authors' contributions}

KL and CS designed the study and wrote the manuscript. SC and NP performed the statistical analysis and revised the manuscript. SV and JT performed the retrospective analyses and revised the manuscript. All authors read and approved the final manuscript.

\section{Ethics approval and consent to participate}

The study protocol was reviewed and approved by the Medical Ethics Committee of Navamindradhiraj University (Bangkok, Thailand). Informed consent was obtained from all patients prior to enrollment.

\section{Patient consent for publication}

Not applicable.

\section{Competing interests}

The authors declare that they have no competing interests.

\section{References}

1. 1993 revised classification system for HIV infection and expanded surveillance case definition for AIDS among adolescents and adults. MMWR Recomm Rep 41: 1-19, 1992.

2. Indian Council of Medical Research. National Cancer Registry Programme: National Printing Press, India: Bangalore, 60-61, 2001.

3. Hong JH, Tsai CS, Lai CH, Chang TC, Wang CC, Chou HH, Lee SP and Hsueh S: Recurrent squamous cell carcinoma of cervix after definitive radiotherapy. Int J Radiat Oncol Biol Phys 60: 249-257, 2004.

4. Perez CA, Grigsby PW, Camel HM, Galakatos AE, Mutch D and Lockett MA: Irradiation alone or combined with surgery in stage IB, IIA, and IIB carcinoma of the uterine cervix: Update of a nonrandomized comparison. Int J Radiat Oncol Biol Phys 31: 703-716, 1995.

5. Greenwald RJ, Freeman GJ and Sharpe AH: The B7 family revisited. Annu Rev Immunol 23: 515-548, 2005.

6. Parsa AT, Waldron JS, Panner A, Crane CA, Parney IF, Barry JJ, Cachola KE, Murray JC, Tihan T, Jensen MC, et al: Loss of tumor suppressor PTEN function increases B7-H1 expression and immunoresistance in glioma. Nat Med 13: 84-88, 2007.

7. Marzec M,Zhang Q, Goradia A, Raghunath PN,Liu X,Paessler M, Wang HY, Wysocka M, Cheng M, Ruggeri BA and Wasik MA: Oncogenic kinase NPM/ALK induces through STAT3 expression of immunosuppressive protein CD274 (PD-L1, B7-H1). Proc Natl Acad Sci USA 105: 20852-20857, 2008.

8. Taube JM, Anders RA, Young GD, Xu H, Sharma R, McMiller TL, Chen S, Klein AP, Pardoll DM, Topalian SL and Chen L: Colocalization of inflammatory response with B7-h1 expression in human melanocytic lesions supports an adaptive resistance mechanism of immune escape. Sci Transl Med 4: 127ra37, 2012.

9. Wu P, Wu D, Li L, Chai Y and Huang J: PD-L1 and survival in solid tumors: A Meta-analysis. PLoS One 10: e0131403, 2015.

10. Hino R, Kabashima K, Kato Y, Yagi H, Nakamura M, Honjo T, Okazaki T and Tokura Y: Tumor cell expression of programmed cell death-1 ligand 1 is a prognostic factor for malignant melanoma. Cancer 116: 1757-1766, 2010.

11. Velcheti V, Schalper KA, Carvajal DE, Anagnostou VK, Syrigos KN, Sznol M, Herbst RS, Gettinger SN, Chen L and Rimm DL: Programmed death ligand-1 expression in non-small cell lung cancer. Lab Invest 94: 107-116, 2014. 
12. Shi SJ, Wang LJ, Wang GD, Guo ZY, Wei M, Meng YL, Yang AG and Wen WH: B7-H1 expression is associated with poor prognosis in colorectal carcinoma and regulates the proliferation and invasion of HCT116 colorectal cancer cells. PLoS One 8: e76012, 2013.

13. Green MR, Monti S, Rodig SJ, Juszczynski P, Currie T, O'Donnell E, Chapuy B, Takeyama K, Neuberg D, Golub TR, et al: Integrative analysis reveals selective 9p24.1 amplification, increased PD-1 ligand expression, and further induction via JAK2 in nodular sclerosing Hodgkin lymphoma and primary mediastinal large B-cell lymphoma. Blood 116: 3268-3277, 2010

14. Barrett MT, Anderson KS, Lenkiewicz E, Andreozzi M, Cunliffe HE, Klassen CL, Dueck AC, McCullough AE, Reddy SK, Ramanathan RK, et al: Genomic amplification of 9p24.1 targeting JAK2, PD-L1, and PD-L2 is enriched in high-risk triple negative breast cancer. Oncotarget 6: 26483-26493, 2015.

15. Cancer Genome Atlas Research Network: Comprehensive molecular characterization of gastric adenocarcinoma. Nature 513: 202-209, 2014

16. Howitt BE, Sun HH, Roemer MG, Kelley A, Chapuy B, Aviki E, Pak C, Connelly C, Gjini E, Shi Y, et al: Genetic basis for PD-L1 expression in squamous cell carcinomas of the cervix and vulva. JAMA Oncol 2: 518-522, 2016.

17. Eltom MA, Jemal A, Mbulaiteye SM, Devesa SS and Biggar RJ: Trends in Kaposi's sarcoma and non-Hodgkin's lymphoma incidence in the United States from 1973 through 1998. J Natl Cancer Inst 94: 1204-1210, 2002.

18. Schneider E, Whitmore S, Glynn KM, Dominguez K, Mitsch A and McKenna TM; Centers for Disease Control and Prevention (CDC): Revised surveillance case definitions for HIV infection among adults, adolescents, and children aged $<18$ months and for HIV infection and AIDS among children aged 18 months to $<13$ years-United States, 2008. MMWR Recomm Rep 57: 1-12, 2008.

19. Shiels MS, Pfeiffer RM, Gail MH, Hall HI, Li J, Chaturvedi AK, Bhatia K, Uldrick TS, Yarchoan R, Goedert JJ and Engels EA: Cancer burden in the HIV-infected population in the United States. J Natl Cancer Inst 103: 753-762, 2011.

20. Kelly H, Weiss HA, Benavente Y, de Sanjose S and Mayaud P: Association of antiretroviral therapy with high-risk human papillomavirus, cervical intraepithelial neoplasia, and invasive cervical cancer in women living with HIV: A systematic review and meta-analysis. Lancet HIV 5: e45-e 58, 2018.

21. Chow WA, Jiang CL and Guan M: Anti-HIV drugs for cancer therapeutics: Back to the future? Lancet Oncol 10: 61-71, 2009.

22. Hofmann M, Stoss O, Shi D, Buttner R, van de Vijver M, Kim W, Ochiai A, Ruschoff $\mathbf{J}$ and Henkel T: Assessment of a HER2 scoring system for gastric cancer: Results from a validation study. Histopathology 52: 797-805, 2008.

23. Topalian SL, Hodi FS, Brahmer JR, Gettinger SN, Smith DC, McDermott DF, Powderly JD, Carvajal RD, Sosman JA, Atkins MB, et al: Safety, activity, and immune correlates of anti-PD-1 antibody in cancer. N Engl J Med 366: 2443-2454, 2012.

24. Inoue Y, Yoshimura K, Mori K, Kurabe N, Kahyo T, Mori H, Kawase A, Tanahashi M, Ogawa H, Inui N, et al: Clinical significance of PD-L1 and PD-L2 copy number gains in non-small-cell lung cancer. Oncotarget 7: 32113-32128, 2016.

25. Dryden-Peterson S, Bvochora-Nsingo M, Medhin H, Suneja G, Asmelash A, Pusoentsi M, Russell A, Efstathiou J, Chabner B, Lockman S, et al: HIV infection and survival among women with cervical cancer. J Clin Oncol 34: 3749-3757, 2016.

26. Batman G, Oliver AW, Zehbe I, Richard C, Hampson L and Hampson IN: Lopinavir up-regulates expression of the antiviral protein ribonuclease $\mathrm{L}$ in human papillomavirus-positive cervical carcinoma cells. Antivir Ther 16: 515-525, 2011.
27. Xulu KR and Hosie MJ: HAART induces cell death in a cervical cancer cell line, HCS-2: A scanning electron microscopy study. J Microsc Ultrastruct 5: 39-48, 2017.

28. Tsushima F, Tanaka K, Otsuki N, Youngnak P, Iwai H, Omura K and Azuma M: Predominant expression of B7-H1 and its immunoregulatory roles in oral squamous cell carcinoma. Oral Oncol 42: 268-274, 2006.

29. Ritprajak P and Azuma M: Intrinsic and extrinsic control of expression of the immunoregulatory molecule pd-11 in epithelial cells and squamous cell carcinoma. Oral Oncol 51: 221-228, 2015.

30. Tudela EV, Singh MK, Lagman M, Ly J, Patel N and Venketaraman V: Cytokine levels in plasma samples of individual with HIV infection. Austin J Clin Immunol 1: 1003, 2014

31. De Luca A, Giancola ML, Cingolani A, Ammassari A, Murri R and Antinori A: Circulating levels and ex vivo production of beta-chemokines, interferon gamma, and interleukin 2 in advanced human immunodeficiency virus type 1 infection: The effect of protease inhibitor therapy. AIDS Res Hum Retroviruses 16: 835-843, 2000.

32. Watanabe D, Uehira T, Yonemoto H, Bando H, Ogawa Y, Yajima K, Taniguchi T, Kasai D, Nishida Y and Shirasaka T: Sustained high levels of serum interferon-gamma during HIV-1 infection: A specific trend different from other cytokines. Viral Immunol 23: 619-625, 2010.

33. Piconi S, Trabattoni D, Fusi ML, Milazzo F, Dix LP, Rizzardini G, Colombo F, Bray D and Clerici M: Effect of two different combinations of antiretrovirals (AZT $+\mathrm{ddI}$ and AZT $+3 \mathrm{TC}$ ) on cytokine production and apoptosis in asymptomatic HIV infection. Antiviral Res 46: 171-179, 2000.

34. Inoue $\mathrm{Y}$, Matsuura S, Kurabe N, Kahyo T, Mori H, Kawase A, Karayama M, Inui N, Funai K, Shinmura K, et al: Clinicopathological and survival analysis of Japanese patients with resected non-small-cell lung cancer harboring NKX2-1, SETDB1, MET, HER2, SOX2, FGFR1, or PIK3CA gene amplification. J Thorac Oncol 10: 1590-1600, 2015.

35. Boulware DR, Meya DB, Bergemann TL, Williams D, Vlasova-St Louis IA, Rhein J, Staddon J, Kambugu A, Janoff EN and Bohjanen PR: Antiretroviral therapy down-regulates innate antiviral response genes in patients with AIDS in sub-saharan Africa. J Acquir Immune Defic Syndr 55: 428-438, 2010.

36. Massanella M, Singhania A, Beliakova-Bethell N, Pier R, Lada SM, White CH, Pérez-Santiago J, Blanco J, Richman DD, Little SJ and Woelk CH: Differential gene expression in HIV-infected individuals following ART. Antiviral Res 100: 420-428, 2013.

37. Maggiorella L, Wen B, Frascogna V, Opolon P, Bourhis J and Deutsch E: Combined radiation sensitizing and anti-angiogenic effects of ionizing radiation and the protease inhibitor ritonavir in a head and neck carcinoma model. Anticancer Res 25: 4357-4362, 2005.

38. Ulrike K, Markus H, Thomas H, Ellen H, Barbara S, Rainer F and Distel LV: NNRTI-based antiretroviral therapy may increase risk of radiation induced side effects in HIV-1-infected patients. Radiother Oncol 116: 323-330, 2015.

39. Borcoman E and Le Tourneau C: Pembrolizumab in cervical cancer: Latest evidence and clinical usefulness. Ther Adv Med Oncol 9: 431-439, 2017.

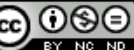

This work is licensed under a Creative Commons Attribution-NonCommercial-NoDerivatives 4.0 International (CC BY-NC-ND 4.0) License. 